\title{
Study on Cross-Cultural Adaptation of Mongolian Students Studying in Japan*
}

\author{
Limei Jia \\ Noraml College of Chifeng University \\ Chifeng, China
}

\author{
Tuge Tao \\ College of Education Science \\ Inner Mongolia University for Nationalities \\ Tongliao, China
}

\begin{abstract}
Mongolian students are not only Chinese minority students, but also an important part of Chinese students studying in Japan. Their cross-cultural adaptation is more severe. In this study, Mongolian students with bachelor's degree, master's degree and doctoral degree were selected as the objects. Through investigation, interview and other research methods, the self-identity, language and communication status of Mongolian students studying in Japan were understood, and the reasons influencing adaptation were analyzed from the perspective of cross-cultural adaptation. The study found that Mongolian students studying in Japan first identified themselves as Mongolian and then Chinese students studying abroad. In school learning, they are easier to master Japanese because of language advantages, and they are easier to form a good interpersonal relationship with surrounding teachers and students because of ethnic identity. In social and cultural life, it is easier to integrate into Japanese society with the idea of inclusiveness.
\end{abstract}

Keywords-Mongolian students; Japanese; cross-cultural adaptation

\section{INTRODUCTION}

Mongolian is an ethnic minority in northern China. Due to its proximity to Japan, Mongolian and Japanese belong to the same Japanese-Mongolian language family, and many other reasons, the number of Mongolia student studying in Japan increases year by year, which plays an important role in enhancing the cultural adaptations is a major problem faced by Mongolian students studying in Japan, which affects their life and communication during their study abroad. This problem has also attracted the attention of researchers at home and abroad. However, most of the current studies are conducted from sociological and psychological perspectives without systematic analysis and in-depth analysis of cross-cultural adaptation of Mongolian students studying in Japan.

Therefore, it is necessary to understand the main manifestations of cross-cultural adaptation of Mongolian students studying in Japan, deeply analyze the influencing factors, and then put forward countermeasures, so as to

*Fund project: National social science foundation's 13th five-year plan 2016 general subject of education "study on cross-cultural adaptation of Mongolian students studying in Japan" stage research results, approval number BMA160025. provide reference for the study of rapid adaptation and crosscultural issues of Mongolian students studying in Japan. This study focuses on the following research issues: self-identity; school adjustment problems social acculturation.

\section{LITERATURE REVIEW}

China and Japan have a long history of exchanging students. As early as the Tang dynasty, Japan sent envoys to China to exchange and study with foreign students. With the rise of Japan's economy, modern China began to send Chinese students to study in Japan to learn advanced ideas and technologies. Since China first sent students to study in Japan in 1896, more and more students have been studying in Japan, especially since the reform and opening up. According to survey released by Japanese student support organizations on December 29, 2017, the total number of foreign students studying in Japanese universities and Japanese language schools was 267,042 as of May 1, 2017, an increase of 27,755 students or 11.6 percent over the previous year, the Chinese Leader reported. Among foreign students in Japan, the number of students from the Chinese mainland broke the 100,000 mark, accounting for $40 \%$ of the total, topping the list.

In history, Chinese students studying in Japan have brought up a large number of outstanding intellectuals, who have exerted a profound influence on China's politics, military affairs, economy, education, culture, ideology and academic research. Contemporary Chinese students studying in Japan will certainly have a significant impact on all aspects of Chinese society. However, there are few studies on this historic and far-reaching cross-cultural communication activity in Chinese academic circles, and there is still a lack of comprehensive and in-depth understanding. There is almost no research on cross-cultural issues of Mongolian students studying in Japan.

There are many researches on foreign students in Japan For example, Yasunori Fukuoka's study on cross-cultural adaptation of Korean and North Korean youth in Japan (1993), Shinichi Asano's study on Asian foreigners in Japan (2007), and Keishuu Saneto's study on Chinese students in Japan (2009). These studies mainly research foreign students studying in Japan from the perspective of Japanese scholars, including the cross-cultural adaptation of foreign students studying in Japan, the status of foreign students studying in 
Japan and the basic situation of Chinese students studying in Japan.

There are more researches on Chinese students in Japan. No matter in history or in contemporary times, the number of Chinese students studying in Japan is large, accounting for a large proportion of the number of Japanese students. As early as 1921, the proposal on the education of foreign students in the Republic of China and the records of the conference of the Great Japanese Empire (the 44th session of the parliament) mentioned to students studying in Japan by Jiro Miyafusa. In 1959, the condition of Chinese students(Thammasat Univestiy China Institude, compile 4) study of Chinese students has carried on the special by Tomoo Otstuki, Yoshino Gonndo's study present situation and the subject in the world (1991), Masumi Oka and Hiroki Fukada's "Chinese students and Japan"(1995) and "modern Chinese study abroad in Japan" in Yaozhong Duan(2003), ect. In these studies, the problems faced by overseas students in Japan and Chinese students in study, life and cultural identity in Japan were studied. It can be said that there are indepth studies on Chinese students studying in Japan, but there are few studies on ethnic minorities, especially Mongolian students.

\section{RESEARCH DESIGN AND METHODS}

\section{A. Relevant Theories of Cross-cultural Adaptation}

1) Culture shock: The anthropologist Kalvero Oberg first put forward the concept of "culture shock" in 1960, also known as "culture shock", which refers to the "deep psychological anxiety caused by the loss of the social communication signals and symbols with which one is familiar and is not familiar with the social symbols of the other party". Cross-cultural research has been using this concept to track and investigate the acculturation of foreigners. This kind of psychological anxiety can even produce physiological reaction, such as continuous body fatigue, long term mental stress, lose interest in originally familiar things, to not adapt to the new life, for the solution of the country, to their own values hit confused, doubting new role and identity, such as powerless to the new environment. This kind of shock will be different because of the cultural difference between the culture and the country of study, so the impact will be relatively small. As China and Japan are both Asian countries, Mongolian students studying in Japan share some cultural similarities, which to some extent reduces the cultural impact of Japanese culture on Mongolian students.

2) Adaptation theory: The scholar Young Yun Kim proposed the adaptation theory to discuss the communication and adaptation of foreigners and to analyze the behavior of individuals in different cultures from a dynamic perspective. Adaptation theory holds that in crosscultural communication, the acculturation of individuals or groups in one culture learning from an adjusting to another culture is a long-term acculturation process, which is manifested as a dynamic process of pressure-adjustmentprogress. This process is a spiral process, in the process of progress back and forth, in the process of pressure to advance step by step. As an ethnic minority, Mongolian students adapt to the social culture of Japan during their study in Japan, and what are the different adaptation problems between them and the Han nationality students. The study on these problems can be used for reference by other ethnic minorities to adapt to study in Japan.

\section{B. Research Object and Research Methods}

1) Research objects: The research objects selected in this paper are Mongolian students from China studying in Japan, including students who study abroad directly from the school and social youth who choose to study in Japan, covering a wide range of age stages, from college students to master's and doctoral students.

2) Research methods: Through questionnaire survey, the basic adaptation problems of Mongolian students in Japan were understood, and the common adaptation problems were screened out.

On the basis of questionnaire survey, some representative Mongolian students were interviewed. Some doctoral students have lived in Japan for nearly 10 years, and they have their own opinions on Japanese society and culture, which can reflect the deep-seated problems and thoughts in the process of acculturation.

\section{THE CROSS-CULTURAL ADAPTATION OF MONGOLIAN STUDENTS STUDYING IN JAPAN AND ITS CAUSES}

According to the cross-cultural adaptation theory, the cross-cultural adaptation of Mongolian students studying in Japan is mainly analyzed from the following aspects.

\section{A. Self-identity Problem "Who Am I"}

Identity is an important issue faced by Mongolian students studying in Japan. Chinese students studying in Japan can be divided into Han nationality students and minority students according to their nationality. Mongolian students, as an ethnic minority among Chinese students studying abroad, reflect the characteristics of ethnic minorities in terms of self-identity.

Self-identity tends to be more ethnic, first they think they are Mongolians, then Chinese students studying abroad. There are three reasons.

First, identity is about long-term life experience: they are about being born in China. Most Mongolians lives in the Inner Mongolia autonomous region in northern China, and the majority of Mongolian students studying in Japan live in this region. They grew up in ethnic communities, and have been to consider themselves as Mongolian first. This consciousness has been naturally carried abroad, and also the first to identify with their Mongolian identity in Japan.

Second, identity is related to the cultural origin of China and Japan. During the period of Genghis Khan, the Yuan dynasty had vast territory, and the fierce Mongolian people 
left an indelible impression on the people all over the world. The Japanese also admire Genghis Khan's great military achievements. Now some Japanese even considered they are the descendants of Mongolian. In the Japanese folk, many Japanese consider themselves as the "nephew" of Mongolian. When Mongolian students in Japan and Japanese refer to themselves as Mongolia, they will get more respect, which virtually strengthens their sense of pride and national selfesteem. In social communication, they are more likely to identify with their Mongolian identity and better integrate into Japanese society.

Third, identity is reflected in the name of Mongolian students studying abroad. In daily life, Mongolian people in China only use last name, while surname is only used to distinguish two people with the same name. Because there is no "family name" like Japanese, even respected people are called by their first names. In rural areas of eastern Inner Mongolia, due to early contact with the Han nationality and the influence of Han culture, most Mongolians adopt Chinese names and use Chinese in family and village environments, it means that they are influenced by the Han nationality, from their values, way of thinking to their living habits, without exception. After leaving their upbringing to study in Japan, Mongolian students changed their names to katakana. However, this notation completely ignores the original Mongolian meaning in the Japanese environment. This can lead to the denial of their self-identity based on the name of the party.

As for the identity of Mongolian students studying abroad, the unique characteristics of Mongolian culture should be fully taken into account. On the basis of maintaining the ethnic culture of Mongolian identity, the identity of Chinese and Chinese students studying abroad should be recognized to establish the national consciousness and integrate into the life of studying abroad in Japan.

\section{B. School Adaptation}

1) The language: When it comes to school adaptation of Mongolia students, the first one is language adaptation. Language is the foundation of learning and mastering knowledge in school. You can use Japanese flexibly you can learn Japanese successfully in Japan. Mongolian and Japanese belong to the Altai language family. It is easier for Mongolian to learn Japanese compared with other ethnic groups. Mongolian students can master Japanese quickly. Most of Mongolian students in Japan have trained Japanese in China, they have a certain language foundation; After studying in Japan, they could master Japanese quickly in the language environment, which laid a good foundation for their study in Japan.

Take advantage of innate language, master Japanese quickly and become proficient in learning and life, better grasp the language.

2) Learning to adapt: Many Mongolian students left their homes to study in schools from grasslands when they were young, which cultivated their independent character. After studying in Japan, they can integrate into the school study very quickly. There are many educational difference between China and Japan, but it does not prevent the hardworking Mongolian students from adjusting to the heavy learning task in Japan. The learning environment in Chinese schools in relatively relaxed compared with that in Japan, the Japanese teachers are more strict. Mongolian students also make more efforts to adapt to the changes in their study life.

In term of learning adaptation, Mongolian students should work hard, whether in China or Japan. Within the Japanese education system, it has been a rapid shift in thinking about learning in order to advance academically.

3) Relationships: The main purpose of Mongolian students to go to Japan is to study. Most of their time is spent in school, so their interpersonal relationship in school is also their main interpersonal relationship. Unlike in China, they have more adjustment problems in their relationships.

The first is the teacher-student relationship. Mongolian students study in Japan, mostly for undergraduate and postgraduate study. Due to cross-cultural learning, they will encounter more adaptation problems than Japanese students and need more help from teachers. At this time, the relationship between teachers and students directly affects their learning. In undergraduate, for example, a teacher is full of love and emotion is exquisite, they can pay more attention to students the practical difficulties, not only solve the problems of the school, it is easier to construct a harmonious relationship from the psychology, this is the teachers love is more able to migrate to the school to study hard, improve learning obtain good effect. In the interview, some students mentioned the teacher's concern for them, which helped them to solve many practical problems and made them more qualified to complete their studies. Especially, Mongolian students studying for master's or doctor's degrees in Japan have closer interpersonal relationship with their tutors, who are not only their teachers in academic research, but also their beneficial friends in life. Once talked about a Mongolian students, in the entrance examination, some Mongolian students of low grade in English, the teacher found the situation after asked the reason, the student told the teacher during their learning in China don't take English as a second language learning, but the Chinese. After knowing the situation, teacher apply to the school, the several Mongolian students' second language exam instead of Chinese, the Mongolian students more fair, make their grades in school scholarship funding, is more conductive to help them better complete their studies.

The second is the relationship between classmates. Mongolian students have the most daily contact with their classmates, who spend most of their time studying and living together with them. In China, there have been cases where some college students could not get along with their classmates and thus criminal cases occurred. In Japan, whether Mongolian students can get along with their classmates in an important issue. Mongolian people in Japan have always been friendly to them. As mentioned above, it is easier for Mongolian students to get along with their classmates in Japan than other Chinese students. In the study, 
advocated, there is no mandatory regulation. When international students first arrive in Japan, they will encounter the problem of garbage classification in their life, which will also cause a lot of trouble. It is also a big challenge for them to discard garbage according to the requirements. Littering is a disgrace in Japan, sometimes so serious that people are isolated.

\section{CONCLUSIONS AND SUGGESTIONS}

Whether in China or Japan, Mongolian students will face the interpersonal relationship with other ethnic groups. Mongolian students studying in Japan should learn and integrate into Japanese culture from more perspectives, understand the national psychological characteristics of Japanese people, and better deal with interpersonal relationships in Japan.

\section{Sociocultural Adaptation}

Sociocultural adaptation mainly focuses on the acquisition of cultural skills needed by Mongolian students to effectively operate in Japanese society and cultural environment, mainly including national cultural acculturation and behavioral acculturation.

1) National cultural adaptation: Mongolian students who choose to study in Japan have a certain degree of understanding and recognition of Japanese national culture before they go abroad to study. Only when they like and identify with Japanese culture to a certain extent will they choose to study in Japan, otherwise they may choose to study in other countries they like. Mongolian and Japanese belong to the Altai language family. Geographically, Japan is closer to Inner Mongolia than other developed countries, and is more developed in education, medicine, automobile and electronics. The pace of life and the pressure of study and work in Japanese society are very heavy. It takes a period of time for foreign students to adapt to the completely different environment in Japan. The culture of capitalist countries is a big shock for foreign students.

2) Behavioral adaptation: In Japanese culture, the individual's words and deeds are strict. From the perspective of daily behavior, Japanese peoples pay more attention to etiquette, no matter from the dress or speech and behavior, showing politeness. Mongolia students come from the vast land of Inner Mongolia in China, and many of them come from pastoral areas. The vast grassland makes Mongolian people open-minded and they are more willing to express their emotions. When they first arrive in Japan, they will have more or less difficulties. But soon, under the influence of the general environment in Japan, they also integrated into the new environment of politeness and friendliness.

In Japan, some codes of conduct are quite different from those in China. For example, recently, garbage classification has attracted a lot of attention. Garbage classification in Japan is one of the few countries in the world that can achieve perfection. In China, waste separation is only

\section{A. Conclusions}

Mongolia students studying in Japan have different performance in cross-cultural adaptation due to different age and status.

First, in terms of self-identity, young students show better psychological adaptation and are more likely to think of themselves as Chinese. For the older students, they first consider themselves as a minority, and in Japan they are more inclined to their Mongolian identity, followed by their citizenship of different countries and their status of studying abroad.

Second, Mongolian students studying in Japan can quickly adapt to school life, mainly in term of language, they are easier to master Japanese, and in terms of nationality, they are easier to be accepted by Japanese.

Third, adaptation in the society also shows its own unique characteristics different from those of students of other nationalities and countries. Because of their own national culture and national character, they are more easily integrated into Japanese school learning and social culture, and thus have their own uniqueness. It is expected that Mongolian students studying in Japan will make more contributions to the development of their home land and ethnic areas after they return home.

\section{B. Suggestions}

First, in terms of self-identity, Mongolian students should enhance their national pride and self-esteem, establish a good image of Chinese students, and act as a cultural messenger in cross-cultural communication to promote cultural exchanges between the two countries.

Second, in the adaptation of school and social culture, Mongolian students should make use of their own language advantages and national cultural advantages to learn the advanced points of Japan, establish a good international consciousness, understand the importance of cross-cultural communication from a macro perspective, and further learn cultural knowledge from specific aspects so as to put what they have learned into practice.

[1] W. Berry, John, et al. Immigrant Youth in Cultural Transition. UK: Taylor \& Francis, Lawrence Erlbaum Associates, Inc,2006

[2] Waters, M. Multiple Ethnicities \& Identities in the United States. United States: Temple University Press,2000

\section{REFERENCES}


[3] Xiaoqing Pan. A Study on the Cultural Differences that Affect the Cross-cultural Interpersonal Adaptation of American and Japanese Students Studying in China. China: China Social Sciences Press,2015

[4] Yonghui Liu, Yanhong Qian. Analysis and Discussion on Crosscultural Adaptation of Foreign Students in Japan. China: Journal of Educational Institute of Jilin Province.2017.12

[5] Cheng Zhang. The Development and Influence of the Policy of Chinese Students Studying in Japan After the Reform and Opening up. China: Journal of Hefei University( Comprehensive Edition),2018.8

[6] Hexituge Bao. A Study of the Japanese Education History in Inner Mongolia the First Half of the 20th Century. China: Inner Mongolia University,2016. 